\title{
DNA Sequence-Based Markers for Verification of Ramet-to-Ortet Relationship in Oil Palm (Elaeis guineensis Jacq.)
}

\author{
Claude Bakoumé ${ }^{1}$, Mohamad Y. Aziah ${ }^{2}$, Tangaya Praveena ${ }^{1}$, Chee Keng Teh ${ }^{2}$, Yahya Suzaini ${ }^{2}$, Musa \\ Hamidah $^{3}$, Mohamad S. Jangi ${ }^{1}$, Mohd N. Basiran ${ }^{1}$, Hashim Khairudin ${ }^{2}$, Kulaveersingam Harikrishna ${ }^{1}$ \\ ${ }^{1}$ Sime Darby Technology Centre, Serdang, Selangor, Malaysia; ${ }^{2}$ Sime Darby R \& D Centre, Banting, Selangor, Malaysia; ${ }^{3}$ Sime \\ Darby Biotechnology Laboratory, Port Dickson, Negeri Sembilan, Malaysia. \\ Email: cbakoume@yahoo.fr, claude.bakoume@simedarby.com
}

Received July $3^{\text {rd }}, 2011$; revised August $15^{\text {th }}, 2011$; accepted August $28^{\text {th }}, 2011$.

\begin{abstract}
Since oil palm (Elaeis guineensis Jacq.) does not breed true, tissue culture-derived material is the resource of choice for achieving oil palm homogeneity in terms of growth and yield. Currently, no genomic tagging method is available with which one could verify the ortet (tissue donor oil palm) from which the clonal planting material (ramets) originated, particularly in cases of unsatisfactory performance. Thus, Sime Darby Plantation used 10 genomic microsatellite markers to genotype 8 sets of 5 ramets +1 ortet and 2 single ortets. The average genetic distance $(D)$ among oil palms from the same set of ramets and ortet was 0.0000 with the exception of sets containing off-type ramets $(D=[0.0834$ 0.1505]). The dendrogram showed that the ramets and their ortet of origin formed a sub-cluster, confirming their similarity. The 10 microsatellite markers were valuable to Sime Darby as tools for verification of ramet-to-ortet relationships and for the identification of off-types. Furthermore, the set of 10 markers revealed a high expected heterozygosity $\left(H_{e}=0.634\right)$ that is a high expected heterosis effect on which yield depends.
\end{abstract}

Keywords: Tissue Culture, Ramet-to-Ortet Relationship, off-Type Ramet, Genetic Diversity, SSR Markers, Sime Darby Plantation

\section{Introduction}

Despite all the efforts devoted to producing high oilyielding planting materials, a high level of heterogeneity prevails among plants and contributes to leveling yield to values which maintain the gap with the theoretical yield. In fact, the heterogeneity is characteristic to seed-derived planting materials of most plant species. In Malaysia, oil yields of $14.9 \mathrm{t} / \mathrm{ha}$ have been obtained from the best individual palms of progeny trials [1]. Unfortunately, oil palm trunk has fibrous-like structure composed of numerous vascular bundles, is cambium-less and possesses one unique vegetative meristem, rendering the replication of elite oil-yielding palms by cuttings or grafting impossible. Furthermore, the nonexistence of fully inbred lines is another limitation to the propagation of elite oilyielding oil palms [2]. Thus, clonal propagation of oil palm via tissue culture allows a fast production of elite palms that offer uniformity with high oil yield [3], among other traits. Tissue culture can be a good route for mass production of disease-tolerant planting materials from single tolerant palms.

Cloning of oil palm consists of inducing somatic embryogenesis on calli derived from young and immature cabbage leaves. The oil yield of the best clones is estimated at $21 \%-25 \%$ more than that of seed-derived planting materials [4-8]. One undesirable feature associated with clonal oil palms is the floral abnormality, known as "mantling", that transforms the stamens of both male and female flowers into carpels, inducing the decay of female inflorescences as fruits that are formed are usually aborted [9], thus directly affecting oil production [10]. In general, the rate of abnormality varies from one tissue culture laboratory to another. With a view to reducing the production of abnormal clones to economically viable levels, some preventative measures have been proposed including: i) the cloning of seedlings [11], ii) limitation of the production of clones from each embryogenic callus [2] or iii) adoption of low hormone me- 
dia coupled with high culling rates [12]. Despite the floral abnormality associated with oil palm tissue culture, public interest in oil palm clones remains high. Usually, planters acquire clonal planting materials from different oil palm tissue culture laboratories. Thus, traceability of clones becomes an issue in those cases where the yields are below expectations. Concurrently, tissue culture laboratories would also like to be able to detect off-types, which cannot be identified by the naked eye.

In this article, we assess the capacity of a set of microsatellite markers to verify ramet-to-ortet identity and detect off-type oil palm clones produced by Sime Darby's tissue culture laboratory. Microsatellites or simple sequence repeats (SSRs) are tandem arrays of simple nucleotide motifs that are ubiquitous components of eukaryotic genomes [13]. They are highly polymorphic, owing to variation in the number of repeats [14]. They show co-dominant inheritance, allowing discrimination of homo- and heterozygous states. Furthermore, they are locus-specific (one locus per primer pair), and the polymorphic information content (a measure of discrimination ability) is higher than that of RFLPs [15]. SSRs have been successful in the monitoring of the uniformity of different embryoid lines from a single oil palm clone [12].

\section{Materials and Methods}

\subsection{Plant Material}

A total of 48 leaf samples from oil palms representing 8 sets of 5 ramets +1 ortet were used in the study. The word ortet refers to an oil palm whose tissues have been collected and used for clonal propagation. A ramet is a clonal seedling at the nursery stage. The small number of sets tested is a result of the relatively few original sources of commercial oil palm planting materials. Some of the sets contained from one to three blind contaminants (off-type ramets in the context of ortet-to-ramet filiation). The tissue culture laboratory added off-type ramets to some of the sets to check the usefulness of the SSR marker combinations in identifying off-types. Two more single ortets whose ramets were not available were added in the assessment of the genetic diversity expected within clonal materials exposed to various constraints in the field. The 10 ortets were among the highest yielding tenera oil palms from field 91A of Ampar Tenang Estate and field 96A of Bukit Pelandok Estate, planted in 1991 and 1996, respectively. Field 91A, located in Serdang, had a local alluvium soil series. The mean annual rainfall was $2215 \mathrm{~mm}$ over 127 rainy days, on average, from 1999 to 2008. During the same period, field 96A, with a local alluvium soil series, averaged a yearly rainfall of $1815 \mathrm{~mm}$ over 110 rainy days. The oil palm ramets were raised at Bukit Talang Estate on Jawa soil series where $2145 \mathrm{~mm}$ of rainfall over 124 rainy days was recorded annually, on average, from 1998 to 2008. Details of the ramets and ortets are presented in Table 1.

DNA extraction from $3 \mathrm{~g}$ of fresh leaf tissues and purification of genomic DNA samples were performed according to Doyle and Doyle [16] with minor modifications. Chloroform:isoamyl alcohol $(24: 1, \mathrm{v} / \mathrm{v})$ was used twice for improved removal of cell wall debris, denatured protein and polysaccharides. The DNA pellet was washed twice with a wash buffer (76\% ethanol, $10 \mathrm{mM}$ ammonium acetate). The concentration of DNA for each sample was determined using a NanoDrop 2000 spectrophotometer (NanoDrop Technologies Inc., USA) using $2 \mu \mathrm{l}$ of diluted DNA sample. One aliquot of $100 \mu \mathrm{l}$ at $10 \mathrm{ng} / \mu 1$ DNA concentration was prepared per sample and stored at $4^{\circ} \mathrm{C}$ for SSR analysis.

\subsection{Microsatellite Analysis}

A set of 10 E. guineensis SSR loci isolated by the French Centre de Coopération en Recherche Agronomique pour le Développement (CIRAD) and fluorescently labeled was used for the present study. The 10 SSR loci represented 7 linkage groups out of 16 , hence covering $44 \%$ of the oil palm genome. Table 2 presents the characteristics of the SSR loci.

The PCR amplification of genomic DNA was performed according to Billotte et al. [17] using $12.5 \mu \mathrm{l}$ of final reaction volume containing $25 \mathrm{ng}$ of genomic DNA, $1 \times$ PCR buffer $(10 \mathrm{mM}$ Tris $\mathrm{HCl}, \mathrm{pH} 9.0,50 \mathrm{mM} \mathrm{KCl}$ and $0.1 \%$ Triton $\left.^{\circledR} \mathrm{X}-100\right), 1.5 \mathrm{mM} \mathrm{MgCl}, 200 \mu \mathrm{M}$ of each of the 4 deoxynucleotide triphosphates (dNTPs), 0.5 Unit of Taq DNA polymerase (Promega, USA), $0.2 \mu \mathrm{M}$ of each primer, and sufficient deionized distilled water (dd $\mathrm{H}_{2} \mathrm{O}$ ) to bring the total volume to $12.5 \mu \mathrm{l}$. PCR amplifications were performed in a MJ Research Gradient Cycler (MJ Research, USA). The PCR programme protocol was as follows [17]:

\begin{tabular}{cc}
\hline Step 1 & Denaturation at $94^{\circ} \mathrm{C}$ for 5 minutes \\
Step 2 & Denaturation at $94^{\circ} \mathrm{C}$ for 30 seconds \\
Step 3 & Annealing at $52^{\circ} \mathrm{C}$ for 1 minute \\
Step 4 & Elongation at $72^{\circ} \mathrm{C}$ for 1 minute \\
& Steps 2 to 4 repeated 35 times, then \\
Step 5 & Elongation at $72^{\circ} \mathrm{C}$ for 8 minutes \\
Step 6 & Storage at $4^{\circ} \mathrm{C}$ for 24 hours \\
\hline
\end{tabular}

PCR amplicons were separated by size via electrophoresis in an ABI System $3730 x l$ DNA Analyzer (Applied Biosystems, USA). The system effectively identifies polymorphic microsatellite alleles with a sizing precision of at least $0.15 \mathrm{bp}$. The alleles were sized with reference to 
Table 1. Ortets selected from commercial oil palm plantations and their respective ramets.

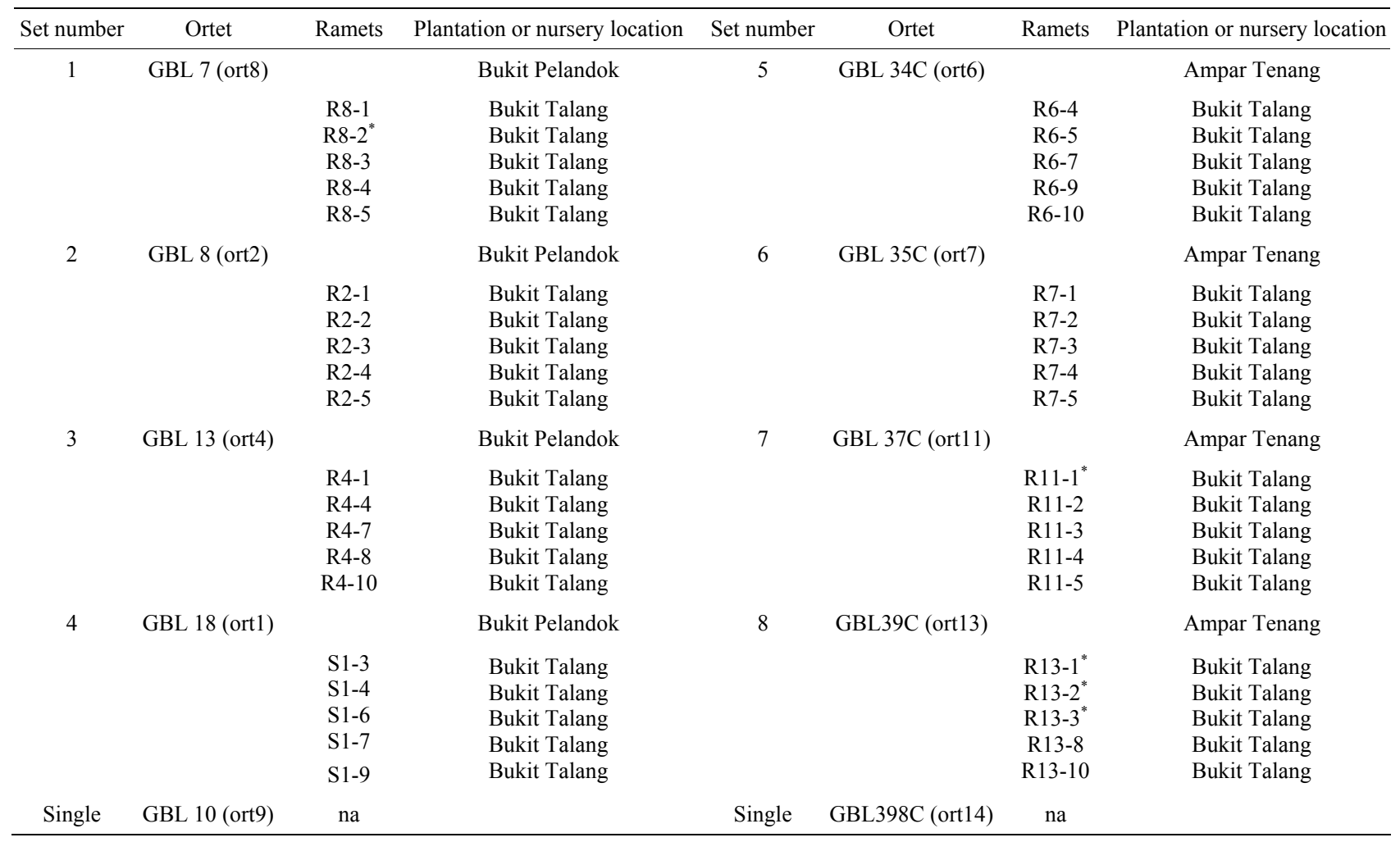

Serial numbers of ortets are given in parentheses; ort1: ortet number 1; R8-1: ramet 1 from ortet 8 ; ${ }^{*}$ : off-type; na: not available.

Table 2. Repeats, primer sequences and expected allele sizes of the 10 SSR markers.

\begin{tabular}{|c|c|c|c|c|c|}
\hline Microsatellite loci & Motif & Primer sequences $\left(5^{\prime}-3^{\prime}\right)$ & Linkage group & Reference allele size (bp) & Annealing temperature $\left({ }^{\circ} \mathrm{C}\right)$ \\
\hline mEgCIR0037 & $(\mathrm{GA}) 17$ & CCAGTCTGCTAACCATCCTATAC & 3 & 175 & 52 \\
\hline mEgCIR0195 & $(\mathrm{GA}) 21$ & CCCACCACCCCTAGCTTCTC & 6 & 255 & 52 \\
\hline $\mathrm{mEgCIR} 0254$ & (TA) $4(\mathrm{GA}) 18$ & СCTTTTGTGCTTTCTTC & 7 & 156 & 52 \\
\hline mEgCIR0257 & $(\mathrm{GA}) 17$ & GCAGCTAGTCACCTGAAC & 1 & 286 & 52 \\
\hline mEgCIR0408 & $(\mathrm{CCG}) 5$ & TTGCGGCCCATCGTAATC & 2 & 193 & 58 \\
\hline $\mathrm{mEgCIR} 0425$ & $(\mathrm{CCG}) 9$ & AGCAAGAGCAAGAGCAGAACT & 3 & 232 & 58 \\
\hline mEgCIR0783 & $(\mathrm{GA}) 15$ & GAATGTGGCTGTAAATGCTGAGTG & 6 & 296 & 58 \\
\hline $\mathrm{mEgCIR} 0790$ & $(\mathrm{GA}) 19$ & TTGGTGGTCCTTTTGAATATC & 12 & 215 & 52 \\
\hline mEgCIR0802 & $(\mathrm{GA}) 12$ & CTCCTTTGGCGTATCCTTTA & 1 & 217 & 52 \\
\hline mEgCIR0825 & (GA) 21 & AGTGAGGTATGGTTGATTAGGA & 10 & 200 & 52 \\
\hline
\end{tabular}

GS500, a formamide containing red DNA size standard (Applied Biosystems, USA). Alleles were generated in the form of electropherogram, where the $\mathrm{X}$-axis scaled the allele sizes in bp and Y-axis the peak intensities. Electropherogram profiles were collected using Data Collection software version 2.0 and the alleles were sized and genotyped using GeneMapper version 4.0 software (Applied Biosystems, USA). Decimal values were rounded to the nearest unit.

\subsection{Data Analysis}

The genotype data were used to study the similarity of the ramets to the ortets and also the identity of one ramet to another, based on estimates of genetic distance [18]. A cluster analysis was performed using the unweighted pair group method with arithmetic (UPGMA) clustering method [19] for a better visualization of the grouping of ortets and derived ramets. Genotypic data from the 10 ortets were used to estimate i) the number of alleles per 
locus $\left(A_{o}\right)$, ii) the observed heterozygosity $\left(H_{o}\right)[20]$, which is the amount of heterozygosity observed at a single locus or an average over several loci, and iii) the expected heterozygosity $\left(H_{e}\right)$ [21], which is an appropriate measure of genetic variability in inbred populations with very few heterozygotes and several homozygote types. The data analysis was carried out by PowerMarker programme [22].

\section{Results}

\subsection{Allele Detection and Genetic Distances}

Alleles were generated in a form of peak intensities on the electropherogram. Homozygote individuals showed a unique peak while heterozygote showed two peaks (Figure 1). The number of alleles per locus varied from 2 at the SSR marker mEgCIR048 to 6 at mEgCIR257 (mean =4.2). The ramet R11-1 revealed unique alleles at SSR markers mEgCIR0037, mEgCIR0257, mEgCIR0790, and mEgCIR0802, and unique genotypes at SSR markers $\mathrm{mEgCIR0254,} \mathrm{mEgCIR0425,} \mathrm{mEgCIR0790,} \mathrm{and} \mathrm{mEg-}$ CIR0802.

The average genetic distance among oil palms from ortet-ramet sets was 0.0000 for 5 out of 8 sets used. The genetic distance within sets varied from 0.1672 in the set No. 7 to 0.6500 in the set No. 1 in sets containing off-type ramets. The genetic distance between the ramets R13-1, R13-2 and R13-3, off-types from set No. 8, was zero. They may have originated from the same ortet. Similarly, the genetic distance between the ramet R8-2, an off-type in the set no.1, and the ortet and ramets from the set No. 3 was zero (Table 3 ). The lowest value $(0.2000)$ of genetic distance among ortets was observed between ortet 1 and ortet 4 , the highest $(0.8500)$ between ortet 1 and ortet 11 , and the mean was average $(0.5308)$. The mean values of the genetic distance between an ortet and its ramets varied from 0.0834 to 0.1505 in the other three sets, which contained off-type ramets (Table 4).

The UPGMA clustering of ortets and ramets based on genetic distance [18] (Figure 2) showed 10 sub-cluster branches, 8 of which grouped ramets with their ortet of provenance while the other two sub-clusters were formed by the off-type ramets: one by R11-1 (sub-cluster II) initially attributed to the set 7 , which individualized earlier in the dendogram, and the second, the sub-cluster III grouping three off-types initially attributed to set 8 from which it separated later to form two different sub-clusters. The off-type ramet R8-2, which originally derived from ortet 8 , joined sub-cluster VII (set 3 from ortet 4).

\subsection{Genetic Diversity among Ortets}

All the 10 microsatellite markers used in this study yielded amplification products. A total of 37 alleles were detected among the 10 ortets. The mean number of alleles $\left(A_{o}\right)$ within ortets was found to be 3.7 , varying from two for microsatellite loci $\mathrm{mEgCIR095}$ and $\mathrm{mEg}$ CIR0408 to 6 for locus mEgCIR0783 (Table 5). Based

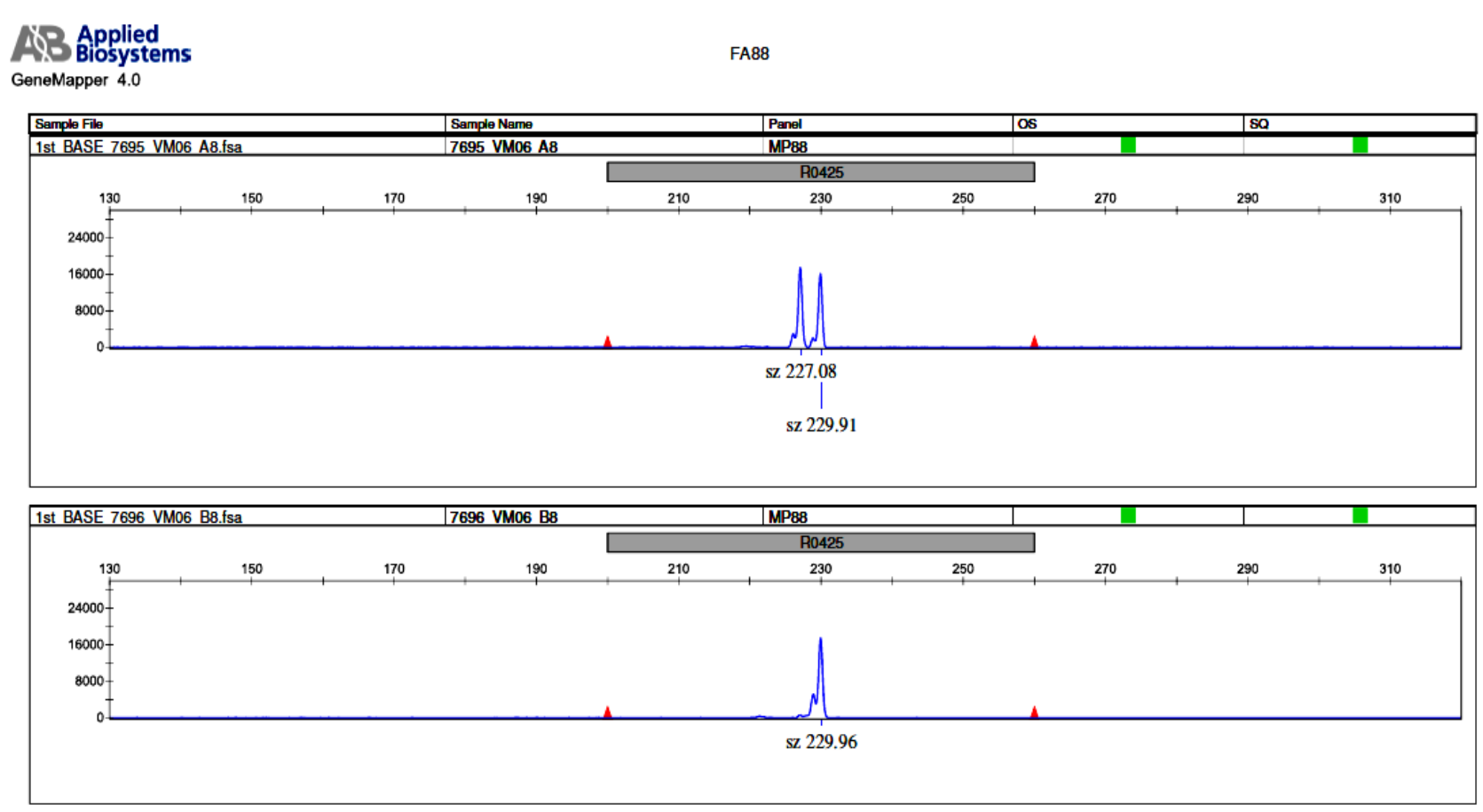

Figure 1. Electropherogram showing two peaks (or two alleles) for a heterozygote oil palm and one peak (one allele) for a homozygote at the microsatellite marker mEgCIR0405. 


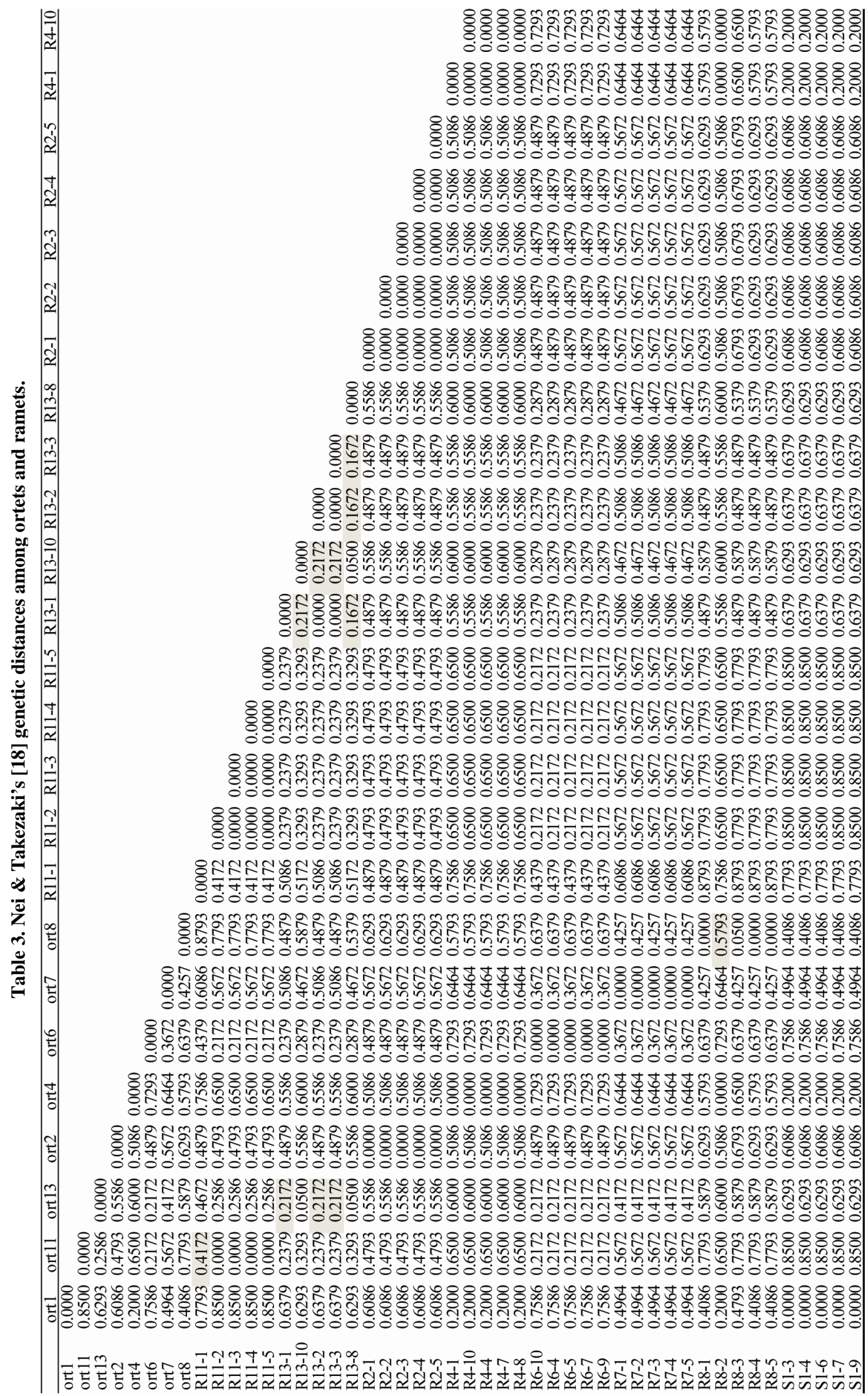




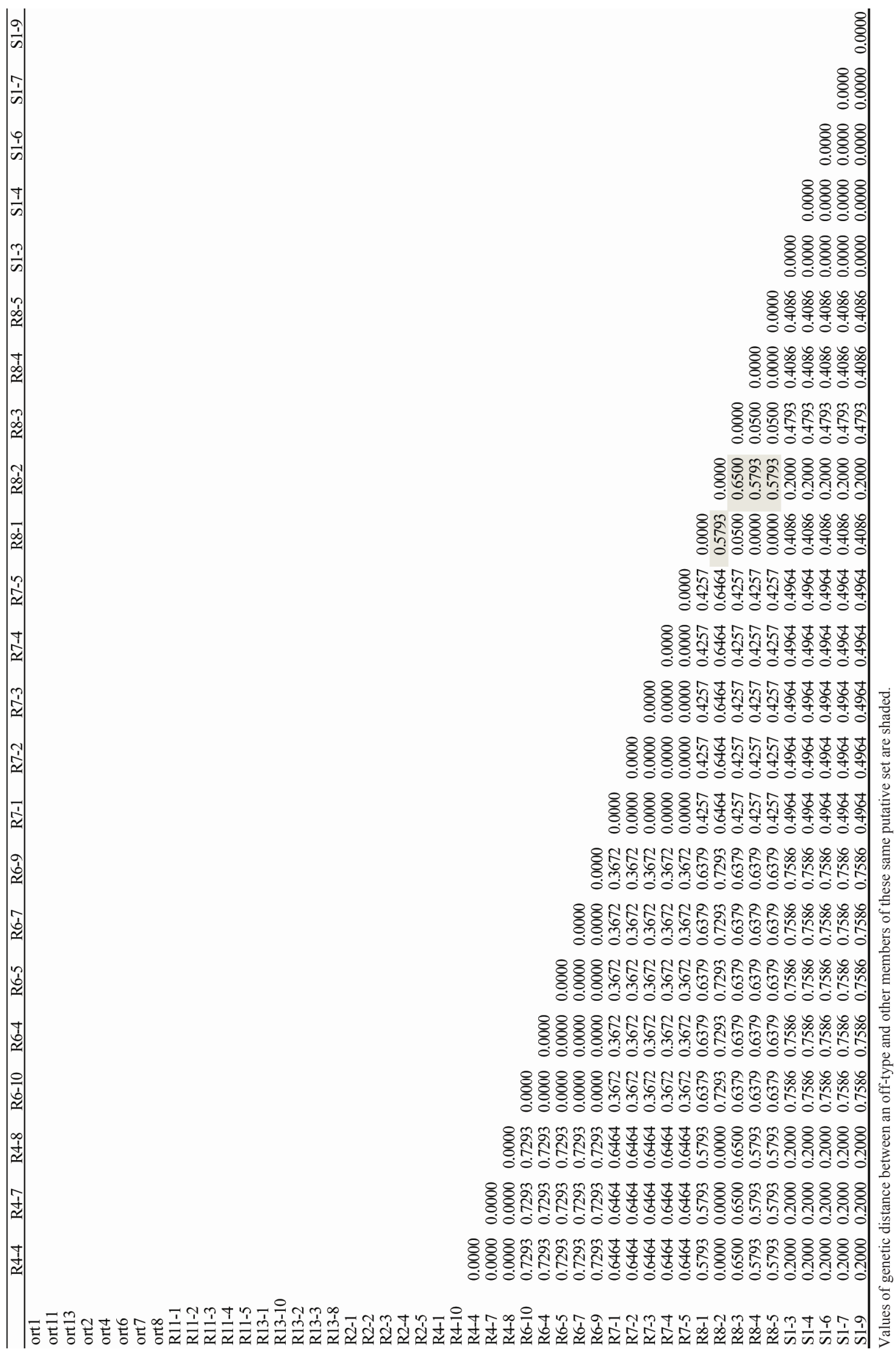


Table 4. Average genetic distance within ortet-ramets sets.

\begin{tabular}{ccccc}
\hline Set No. & Ortet & $\begin{array}{c}\text { Number of } \\
\text { ramets }\end{array}$ & $\begin{array}{c}\text { Number of } \\
\text { off-type ramets }\end{array}$ & $D_{A}$ \\
\hline 1 & GBL 7 (ort8) & 5 & 1 & 0.1259 \\
2 & GBL 8 (ort2) & 5 & 0 & 0.0000 \\
3 & GBL 13 (ort4) & 5 & 0 & 0.0000 \\
4 & GBL 18 (ort1) & 5 & 0 & 0.0000 \\
5 & GBL 34C (ort6) & 5 & 0 & 0.0000 \\
6 & GBL 35C (ort7) & 5 & 0 & 0.0000 \\
7 & GBL 37C (ort11) & 5 & 1 & 0.0834 \\
8 & GBL 39C (ort13) & 5 & 3 & 0.1505 \\
\hline
\end{tabular}

Ort1: ortet number 1, $D_{A}$ : Nei \& Takezaki's [18] genetic distance.

Table 5. Genetic variability parameters within ortets.

\begin{tabular}{cccc}
\hline SSR loci & $A_{o}$ & $H_{o}$ & $H_{e}$ \\
\hline mEgCIR0037 & 5.0 & 0.900 & 0.690 \\
$\operatorname{mEgCIR0195}$ & 2.0 & 0.200 & 0.480 \\
$\operatorname{mEgCIR} 0254$ & 4.0 & 0.900 & 0.715 \\
$\operatorname{mEgCIR} 0257$ & 3.0 & 0.700 & 0.595 \\
$\operatorname{mEgCIR} 0408$ & 2.0 & 0.200 & 0.500 \\
$\operatorname{mEgCIR} 0425$ & 3.0 & 0.700 & 0.620 \\
$\mathrm{mEgCIR} 0783$ & 6.0 & 0.800 & 0.765 \\
$\mathrm{mEgCIR} 0790$ & 5.0 & 0.700 & 0.765 \\
$\mathrm{mEgCIR} 0802$ & 3.0 & 0.600 & 0.645 \\
$\mathrm{mEgCIR} 0825$ & 4.0 & 0.600 & 0.565 \\
Mean & 3.7 & 0.630 & 0.634 \\
\hline
\end{tabular}

on the dinucleotide composition there were two classes of microsatellites, including perfect and compound microsatellites. No clear relation was observable between the two classes and the number of alleles per locus in the study. The observed heterozygosity $\left(H_{o}\right)$ varied from 0.200 for SSR markers mEgCIR0195 and mEgCIR0408 to 0.900 for SSR marker mEgCIR0037 (mean $=0.630)$. The expected heterozygosity $\left(H_{e}\right)$ ranged from 0.480 for SSR marker mEgCIR0195 to 0.765 for SSR markers mEgCIR 0783 and mEgCIR0790 (mean $=0.634$ ). The values of heterozygosity obtained are not related to the number of alleles at the microsatellite locus. Few alleles at a locus lead to high value heterozygosity because ortets were heterozygote for the loci used.

\section{Discussion}

\subsection{Ramet-to-Ortet Genetic Relationship}

The high polymorphism of the microsatellite markers used (i.e. their capacity of revealing even a single nu- cleotide difference among DNA sequences from closely related genotypes) allowed the detection of differences within ortet-ramet sets. The visualization of the genotypic data showed that the ramet R11-1 from set No. 7 was distinct from the ortet and ramets of its putative set as well as from the rest of the ortets and ramets studied. In fact, this ramet got showed unique alleles and unique genotype at certain microsatellite loci, indicating that it was not only an off-type but also not derived from the tissue culture. The ramets R8-2 from set No. 1 and R13-1, R13-2, R13-3 from set No. 8 differed from those of the rest of the members of their respective sets, showing that they were intruders. Cochard [23] also identified illegitimate genetic configurations among oil palms as a first step of his study of the legitimacy of oil palm breeding populations through a visual comparison of genotypic data from a microsatellite analysis.

The genetic distance is a measure of the amount of genetic and is useful for grouping of populations or individuals [24]. In the present study, the genetic distance among ortets and ramets should be understood as the degree to which the various alleles do not occur equally in the oil palms studied. The statistic of Nei and Takezaki [18], also known as Nei and Takezaki's genetic distance $\left(D_{A}\right)$, varies from 0 to 1 with 0 meaning total similarity and 1 total divergence. Thus, for the sets 2, 3, 4, 5, and 6 where the within $D_{A}$ was zero, the ramets derived from tissues collected from their respective ortets. The ramet R8-2, which showed total similarity $\left(D_{A}=0\right)$ to ortet and ramets of the set No. 3, probably derived from the culture of tissues collected from the ortet ort4. The ramets R13-1, R13-2, and R13-3 did not derive from the ortet ort13. Nevertheless, the genetic distance among the three ramets was zero, suggesting that they derived from the same ortet, one not represented in this study.

For a further understanding of the relations between ortets and ramets, the cluster analysis yielded a dendogram according to Nei and Takezaki [18]. In this dendrogram the ramet R8-2, initially included in set no. 1, is seen to be finally joined to the sub-cluster of its ortet of provenance (ortet ort1). It is most likely that the ramets R13-1, R13-2, and R13-3, whose sub-cluster is on the same branch as the sub-cluster of its putative set 3, probably derived from an ortet closely related to the ortet ort13. The dendogram confirmed the uniqueness of ramet R11-1. It has no relationship with any of the ortets used in this study. Cochard [23] also found some incoherence as regards the legitimacy of materials from breeding programme via use of the software Structure which also allows visualization of the relationships among oil palms used as genitors and their putative ascendances.

According to Corley [25], the number of markers needed for identification purposes might be fewer than 


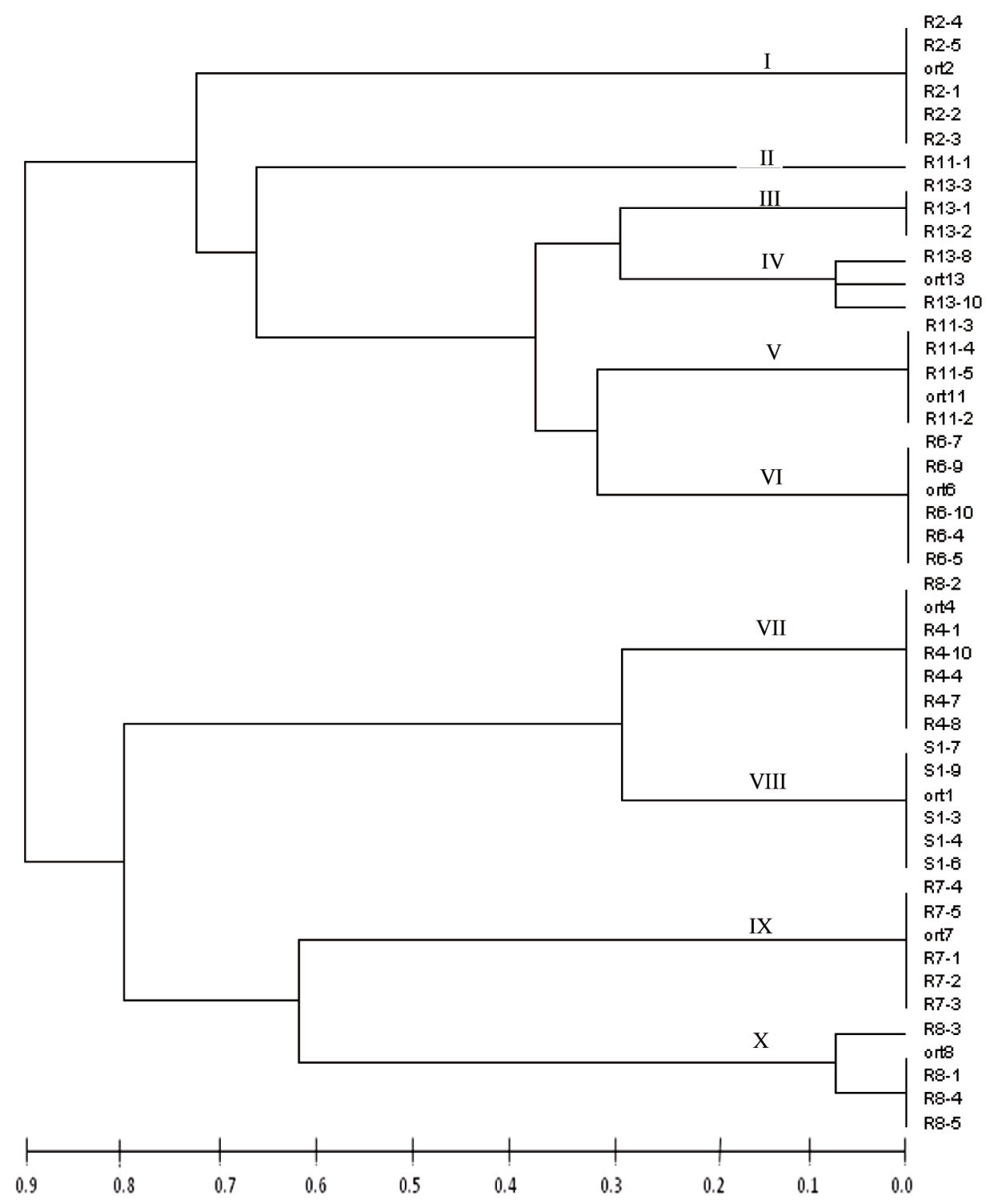

Figure 2. UPGMA clustering of ortets and ramets based on genetic distance over 10 SSR loci. R2-4: 4th ramet derived from ortet number 2, ort2: ortet number 2, S1: ortet number 1, S1-3: 3rd ramet derived from ortet number 1.

five due to their high polymorphism at the locus level. Rajinder et al. [12] obtained satisfactory separation of six ortet-ramet sets using five SSR loci. Limitation of the number of SSR markers to be used for clonal identification and detection of off-types to 5 is justified given the tedious nature of the procedure for the development of SSR markers in general and particularly for oil palm. The procedure involves the building of microsatellite-enriched genomic libraries, following a hybridization-based capture methodology using labeled microsatellite oligoprobes and sequencing of microsatellite-containing sequences [26]. Another concern is with the related high cost of SSR marker development. Nowadays, with the availability of the oil palm genome sequence, microsatel- lite motives are identified through bioinformatics data mining and primers designed accordingly, easing the development of SSR markers and reducing its cost. Furthermore, microsatellites are amenable to high-throughput from DNA extraction to the scoring of amplicons so that large numbers of markers can be analysed with large numbers of samples. Comparing genotypes at 10 SSR loci representing 7 linkage groups (or chromosomes) out of 16 would be more comprehensive because they cover almost half of the oil palm genome.The set of SSR markers used demonstrated a strong capacity for identifying off-type ramets, so it can contribute to the certification of the purity of commercial clonal planting materials. In fact, culture mixtures inevitably happen, given the 
large number of cultures handled in the tissue culture laboratory [12]. Thus, the success of the 10 SSR loci used in showing ramet-to-ortet relationships and clear identification of off-type ramets confirms the main expectation of the study.

\subsection{Genetic Variability within Ortets' Clonal Progenies}

Clonal progenies are duplicates of an ortet. Thus, the genetic variability within ortets well reflects the genetic variability among their clonal progenies. The average number of alleles $\left(A_{o}\right)$ per locus is one of the genetic diversity measures commonly used. The $A_{o}$ found among the 10 ortets studied is relatively high. In a previous assessment of the number of alleles per locus over 21 accessions of oil palms from 7 African countries and one Deli dura using 21 microsatellite loci, the $A_{o}$ was equal to 5.3 [17]. Bakoume et al. [27], using 16 SSR markers, obtained 13.1 alleles per locus over 494 oil palms representing 45 native oil palm populations from 10 African countries, three breeding populations and one semi-wild collection material. A lower value of $A_{o}$ found in the 10 ortets, all of tenera oil palm type, could have been expected. In fact, both the dura and the pisifera, parents of the hybrid (tenera), have a narrow basic allelic diversity. Dura populations (female parents) trace their descent to only four original palms introduced in 1848 in Bogor, Indonesia [28]. Pisifera populations (pollen donors) are derived from only two palms, notably SP540T "Djongo", the best selected in the Palmeraie de la Rive at Eala, Democratic Republic of Congo. Furthermore, selection carried out over years in both the dura and pisifera populations has led to inbreeding and elimination of certain alleles. However, it should be noted that the relatively low $A_{o}$ value detected in the present study could also be related to the small number of ortets available.

Despite the low mean number of alleles per locus, the values of observed $\left(H_{o}\right)$ and expected $\left(H_{e}\right)$ heterozygosities were 0.630 and 0.634 , respectively. The $H_{e}$ value was 0.68 within 21 accessions of oil palm belonging to 7 African countries using 21 SSR markers [17] and, using 16 SSR markers, 0.644 within 49 natural oil palms populations from Africa, breeding populations, and semiwild material [27]. Despite the low mean number of alleles per locus, the value of $H_{e}$ found in this study could be considered high. This value is congruent with breeders' objective of getting as high heterogosity as possible in tenera hydrids released to oil palm growers. A high value of $H_{e}$ implies high heterosis on which oil palm yield depends.

The high $H_{e}$ value found among ortets should be expected among their clonal progenies. The high genetic diversity found in oil palm can explain its plasticity as regards its adaptation to various environments and to its actual large distribution area [29]. Some of the heterotic allelic combinations existing in the ortets may improve the synthesis of more flavonoids, which are compounds that stop or kill pathogens in oil palm [30]. Hence, blending of different oil palm clones during planting in the field may contribute to controlling environmental constraints, including diseases, which are real threats to oil palm plantations, regardless of the continent on which they are found.

\section{Conclusions}

The set of 10 microsatellite markers used in the study successfully traced the ramet-to-ortet relationship and identified off-type ramets. They should be routinely used to verify ramet-to-ortet identity and detect off-type oil palm clones produced by Sime Darby's tissue culture laboratory. The 10 microsatellite markers also revealed a high level of genetic diversity among ortets, which should be expected among their clonal progenies.

\section{Acknowledgements}

The authors would like to express their deepest gratitude to Sime Darby Plantation Sdn Bhd for allowing the publication of this work.

\section{REFERENCES}

[1] N. Rajanaidu and A. Kushairi, "Strategies for the Development of Future Oil Palm Planting Materials," Paper Presented at ISOPB Seminar on the Progress of Oil Palm Breeding and Selection, Medan, 6-9 October 2003.

[2] S. Mayes, F. Hafeez, Z. Price, D. MacDonald, N. Billotte and J. Roberts, "Molecular Research in Oil Palm, the Key Oil Crop for the Future," In: P. H. Moore and R. Ming, Eds., Genomics in Tropical Crop Plants, Nottingham University Press, Nottingham, 2008, pp. 371-404. doi:10.1007/978-0-387-71219-2 15

[3] G. Van Der Linden, S. A. Sharifah, G. Angenent, S. C. Cheah and R. Smulders, "Molecular Characterization of Flower Development in Oil Palm in Relation to the Mantling Abnormality," Proceedings MPOB 2001 International Palm Oil Congress-Agriculture, Kuala Lumpur, 2005, pp. 531-549.

[4] V. Le Guen, G. Samaritaan, Z. Othman, C. W. Chin, K. E. Konan and T. Durand-Gasselin, "Oil Production in Young Oil Palm Clones," Oleagineux, Vol. 46, 1991, pp. 347-359.

[5] Y. Duval, P. Amblard, A. Rival, E. Konan, S. Gogor and T. Durand-Gasselin, "Progress in Oil Palm Tissue Culture and Clonal Performance in Indonesia and Côte d'Ivoire," Proceedings ISP Conference Plantation Management for 21st Century, Kuala Lumpur, 1997, pp. 291-307.

[6] A. B. Maheran and O. Abu Zarin, "Felda's Experience in Clonal Oil Palm Planting on Inland Soils," Proceedings 
of the PORIM Oil Palm Congress, Kuala Lumpur, 1999, pp. 330-343.

[7] A. C. Soh, Y. Y. Yong, Y. W. Ho and N. Rajanaidu, "Commercial Potential of Oil Palm Clones: Early Results of Their Performances," In: V. Rao, I. E. Henson and N. Rajanaidu, Eds., Recent Developments in Oil Palm Tissue Culture and Technology, Palm Oil Research Institute of Malaysia, Kuala Lumpur, 1995, pp. 134-144.

[8] A. C. Soh, G. Wong, C. C. Tan, P. S. Chew, T. Y. Hor, S. P. Chong and K. Gopal, "Recent Advances towards ComMercial Production of Elite Oil Palm Clones," Proceedings of the MPOB 2001 International Palm Oil Congress-Agriculture, Kuala Lumpur, 2001, pp. 33-44.

[9] C. J. Eeuwens, S. Lord, C. R. Donough, V. Rao, G. Vallejo and S. Nelson, "Effects of Tissue Culture CondiTions during Embryoid Multiplication on the Incidence of 'Mantled' Flowering in Clonal Propagated Oil Palm," Cell Plant, Tissue Organ Culture, Vol. 70, 2002, pp. 311-323. doi:10.1023/A:1016543921508

[10] S. Jouannic, X. Argout, F. Lechauve, C. Fizames, A. Borgel, F. Morcillo, F. Aberlec-Bertossi, Y. Duval and J. W. Tregear, "Analysis of Expressed Sequence Tags from Oil Palm (Elaeis guineensis)," FEBS Letters, Vol. 579, 2005, pp. 2709-2714. doi:10.1016/j.febslet.2005.03.093

[11] A. C. Soh, G. Wong, C. C. Tan, T. Y. Hor and C. K. Wong, "Revisited: Cloning Seedling of Reproduced Best Dxp Cross Strategy," Paper Presented at ISOPB Seminar on the Progress of Oil Palm Breeding and Selection, Medan, 6-9 October 2003.

[12] S. Rajinder, N. Jayanthi, T. Soon-Guan, M. P. Jothi and S. C. Cheah, "Development of Simple Sequence Repeat (SSR) Markers for Oil Palm and Their Application in Genetic Mapping and Fingerprinting of Tissue Culture Clones," Asia Pacific Journal of Molecular Biology and Biotechnology, Vol. 15, 2007, pp. 121-131.

[13] M. Delseny, M. Laroche and P. Penon, "Detection of Sequences with Z-DNA Forming Potential in High Plants," Biochemical and Biosphysical Research Commununications, Vol. 116, 1983, pp. 113-120. doi:10.1016/0006-291X(83)90388-1

[14] W. Amos, S. J. Sawcer, R. W. Feakes and D. C. Rubinsztein, "Microsatellites Show Mutational Bias and Heterozygote Instability," Nature Genetics, Vol. 13, 1996, pp. 390-391. doi:10.1038/ng0896-390

[15] J. S. C. Smith, E. C. L. Chin, H. Shu, O. S. Smith, S. J. Wall, M. L. Senior, S. E. Mitchel, S. Kresovich and J. Ziegle, "An Evaluation of the Utility of SSR Loci as MoLecular Markers in Maize (Zea mays L.), Comparisons with Data from RFLPs and Pedigree," Theoretical and Applied Genetics, Vol. 95, 1997, pp. 163-173. doi:10.1007/s001220050544

[16] J. Doyle and L. Doyle, "Isolation of Plant DNA from Fresh Tissue," Focus, Vol. 12, 1990, pp. 13-15.

[17] N. Billotte, N. A. M. Risterucci, E. Barcelos, L. Noyer, P. Amblard and F. C. Baurens, "Development, Characterisa- tion, and Across-Taxa Utility of Oil Palm (Elaeis guineensis Jacq.) Microsatellite Markers," Genome, Vol. 44, 2001, pp. 413-425.

[18] M. Nei and N. Takezaki, "Estimation of Genetic Distances and Phylogenetic Trees from DNA Analysis," Proceedings of the 5th World Congress on Genetics. Applied to Livestock Production, Vol. 21, 1983, pp. 405412.

[19] P. H. A. Sneath and R. R. Sokal, "Numerical Taxonomy," W. H. Freeman Press, San Francisco, 1973.

[20] B. S. Weir, "Genetic Data Analysis II," MA: Sinauer Associates, Inc., Sunderland, 1996.

[21] M. Nei, "Analysis of Gene Diversity in Subdivided Populations," Proceedings of the National Academy of Science of the USA, Vol. 70, 1973, pp. 3321-3323. doi:10.1073/pnas.70.12.3321

[22] K. Liu and S. V. Muse, "PowerMarker: Intergrated Analysis Environment for Genetic Marker Data," Bioinformatics, Vol. 21, 2005, pp. 2128-2129. doi:10.1093/bioinformatics/bti282

[23] B. Cochard, "Etude de la Diversité Génétique et du Déséquilibre de Liaison au Sein de Populations Améliorées de Palmier à Huile (Elaeis guineensis Jacq.)," Ph.D. Dissertation, SUPAGRO, Montpellier, 2008.

[24] F. C. Yeh, "Population Genetics," In: A. Young, D. Boshier and T. Boyle, Eds., Forest Conservation Genetics: Principles and Practice, CSIRO Publishing, Collingwood, 2000, pp. 21-37.

[25] R. V. H. Corley, "Illegitimacy in Oil Palm Breeding," Journal of Oil Palm Research, Vol. 17, 2005, pp. 64-69.

[26] N. Billotte, P. J. L. Lagoda, A. M. Risterucci and F. P. Baurens, "Microstellite-Enriched Libraries: Applied Methodology for the Development of SSR Markers in Tropical Crops," Fruits, Vol. 54, 1999, pp. 277-288.

[27] C. Bakoumé, R. Wickneswari, N. Rajanaidu, A. Kushairi, P. Amblard and N Billotte, "Allelic Diversity of Natural Oil Palm (Elaeis guineensis Jacq.) Populations Detected by Microsatellite Markers: Implication in Conservation," Plant Genetic Resources Characterization and Utilization, Vol. 5, 2007, pp. 104-107. doi: $10.1017 /$ S1479262107710870

[28] C. W. S. Hartley, "The Oil Palm (Elaeis guineensis Jacq.)," Longman Scientific and Technical, New York, 1988.

[29] C. Bakoumé, "Genetic Diversity of Natural Oil Palm (Elaeis guineensis Jacq.) Populations Using Microsatellite Markers," unpublished Ph.D. dissertation, Universiti Kebangsaan Malaysia, Bangi, 2006.

[30] S. Diabate, H. De Franqueville, D. Allou, K. E. Konan, O. A. Coulibaly and W. P. N'Guessan, "Phenolic Diversity in the Defense Reaction of the Oil Palm against Vascular Wilt Disease," Proceedings of the 2009 International Palm Oil Congress on Palm Oil: Balancing Ecologics with Economics, Kuala Lumpur, 2009, pp. 1027-1034. 